\title{
The Complexity of Corporate Governance and Its Impact on Internal Audit Independence
}

By

Lily Bi, University of South Florida

$\mathrm{T}$ he internal audit function is the central point of interest for management and the board of directors as its role is to help the organization accomplish its objectives by improving its governance, risk management, and internal control pro cesses. Internal audit independence lays the foundation for its assurance services. Although the Institute of Internal Auditors (IIA) requires that chief audit executives (CAE) report to the board to ensure internal audit independence, regulations are silent on

An internal audit function provides assurance of the effectiveness of the organization's risk management. The realization of the function's strategic role depends on its independence. How does corporate governance impact internal audit independence? this requirement. The variances of governance models added complexity. CAEs' relationship with the board differs depending on the organization's board structures.

Tradition, history, culture, and legal systems have created the world's diverse corporate governance models. The three typical representations of governance models are the Anglo-American, the Germanic, and the Japanese (Clarke, 2016). The Anglo-American model, also known as the one-tier board model, is widely adopted in the publicly traded companies in the United States (US), United King dom (UK), Canada, Australia, and New Zealand.

The Germanic model, also called the two-tier board model, is widely adopted in the publicly traded companies in Germany, Austria, Switzerland, Sweden, and Denmark. The Japanese model, called the hybrid board model in this paper, is adopted in the publicly traded companies in Japan and China.

Keywords: audit committee, board, board structure, corporate governance, internal audit independence, IIA Standards 
There have been many academic articles on corporate governance, internal audit independence, and the value of an internal audit function to corporate governance. However, no research has yet analyzed corporate governance's impact on the independence of internal audit. This study focuses on the three representative governance models and investigates two research questions:

RQ1: Do the corporate governance factors impact internal audit independence?

RQ2: Do the corporate governance factors impact actual internal audit practices?

As governance has many elements and dimensions of complexity, I selected the following factors pertinent to IAFs: 1) the board structures - whether the organization adopts a one-tier, two-tier, or hybrid board; this factor corresponds with the three governance systems, 2) whether an audit committee exists in the organization, and 3) whether internal audit function is mandated by law.

\section{Findings and Conclusions}

Though the IIA Standards prescribe several requirements for internal audit independence so auditors can perform their duties, the research reveals an alarming fact that these requirements are not conformed by internal audit functions around the world. Without independence, one could question how the internal audit function provides assurance on the organization's risk management and internal control processes.

The study revealed that the organization's board structure is a significant factor impacting internal audit independence and internal audit practices, e.g. board support of internal audit functions, sufficiency of internal audit function's budget, internal audit free access to organization's records, internal audit communicating unacceptable risks to the board, and CAE meeting with audit committee in executive session. In addition, internal audit functions that are mandated by law are more likely to be independent than those opposite. Internal audit practices are positively associated with internal audit independence. Internal audit functions that have higher levels of independence are more likely to be supported by the

\section{Methodology}

Quantitative research objectively tests theories by investigating the relationships among variables that are statistically analyzed to draw a conclusion. Following Creswell's methodology, I utilized the data from the 2015 IIA's global survey and selected five countries representing the three governance models to investigate the factors impacting internal audit independence and how the internal audit independence is reflected in the actual practices.

board, have sufficient budget and unrestricted access to the organization's records.

The research conclusion that the board structure and internal audit mandate are two significant factors impacting internal audit independence and practices is significant and applicable to the enhancement of corporate governance. To some extent, the CAE's relationship with the board determines the positioning of the internal audit function, reinforces its authority, and can have a significant impact on its effectiveness. This study adds empirical evidence to the literature that the board structures impact internal audit independence and audit practices. It suggests that IIA recognize the different board structures provide clear guidance on the relationship between CAE and the board. Furthermore, it provides evidence for Security Exchanges to update their Governance Codes in mandating internal audit functions and clearly specifying the CAE reporting line to an independent board.

\section{Where to Find Out More}

For questions and correspondence, please send email to lily.bi@theiia.org.

\begin{tabular}{l}
\multicolumn{1}{c|}{ Review } \\
This article was accepted under the constructive \\
peer review option. For futher details, see the de- \\
scriptions at: \\
http://mumabusinessreview.org/peer-review-op- \\
tions/
\end{tabular}

\section{Author}

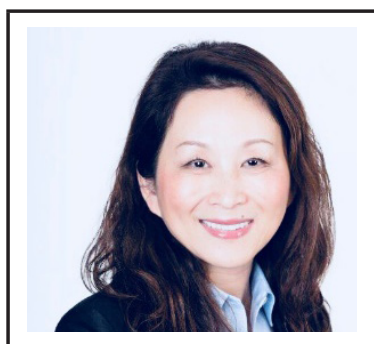

Lily Bi serves as the Vice President of The IIA's Global Certifications. She oversees all facets of the IIA's Global Certifications, provides the strategic direction and management of all certification programs and exam development impacting over 300,000 candidates or certified individuals around the world. Lily has 30 years' global experience in internal audit, risk management, IT, and business management. She gained global perspectives through direct career experience in the United States, Japan, Singapore, and China. She received the Doctor in Business Administration degree in December 2019. 